tubo is then moved through a distance of four inches to a point two inches on the sher side of the zero, in a horizontal direction, from which the second exposure is given. On developing the plate the cross wires and two shadows of the foreign body are seen. By means of a sliding caliper scale, which I have had specially engraved for the heights of 15 and 20 inches, the actual depth of the foreign body from the plate may immediately be read off from the instrument, after placing the fixed jaw of the scale on one part of the first shadow and sliding the moveable jaw along till it points to the corresponding part of the second shadow. ${ }^{1}$ It is often, however, found aclvisable in cases where the foreign body is less than one inch from the surface to increase the distance through which the $\mathrm{x}$-ray tube is moved to eight inches instead of four inches (i.e., four inches on each side of the zero). By this means the distance between the shadows is increased and consequently a more accurate result obtained but with some distortion of the images. of course, it must be remembered that by doubling the distance through which the tube is moved the reading on the scale must be halved to give the true depth of the foreign body from the plate.

In rapid work, when great accuracy is not required or when photographic plates cannot be obtained, the screen, fitted with cross wires and a thin sheet of transparent celluloid on which the shadows may be marked, is employed in exactly a similar manner. In using the screen, however. it is advisable to work with a distance of only 10 inches (measuring from screen to anode) instead of 20 inches. 'The reading on the 20 -inch scale must necessarily be halved to obtain the true depth of the foreign body from the screen. It must, nevertheless, be admitted that localisation by this means is not as satisfactory as when negatives are employed since the shadows are generally lacking in definition. It is obvious that this direct-reading localising scale, which only measures eight inches in length, has a great advantage over the other and more cumbersome localisers in use.

The above method is founded on the principle described by Mr. J. Mackenzie Davidson but it is more compact and simple.

Blackheatl.

\section{d dittiror}

\section{HOSPITAL PRACTICE,}

\section{BRITISH AND FOREIGN.}

Nulla autem est alia pro certo noscendi via, nisi quamplurimas et morborum et dissectionum historias, tum aliorum tum proprias collectas habere, et inter so comparare.-MorangNI De Sed. et Caus. Morb., lib. iv., Procmium.

\section{ST. GEORGE'S HOSPITAL.}

an UnUSUal Case of INTUSSUsception; operation; RECOVERY

(Under the care of Mr. H. S. Pendeleiury.)

WE have published in the "Mirror of Hospital Practice" numerous cases of intussusception in which early operation was successful in saving life. The following case is a valuable addition to the series, for it demonstrates clearly the utter unlikelihood of a reduction of the invagination by any method of injection or inflation. The indurated iliac intussusception which was last reduced could be amenable only to direct surgical treatment. The practice of employing inflation or injection for the reduction of an intussusception is yearly less frequently seen and the value of an early laparotomy is more and more recognised. The best results will be obtained when the public have learnt the importance of the early symptoms of the disease and the danger of purgatives. For the notes of the case we are indebted to Mr. Adrian Caddy, house surgeon.

A boy, aged two years, was admitted into St. George's Hospital on Dec. 29th, 1901. The child had had a large meal of nuts on the 26th; in the afternoon of the 28th he was seized with sudden acute abdominal pain, followed by vomiting, and in a few hours' time by the discharge of much mucus

1 The instrument may bo obtained from $L$. Miller, manufacturing elect rícian, 93, Hatton-garden, London, E.C. and some blood from the rectum. The vomiting and rectal discharge continued and Dr. G. E. Hale was called in. $\mathrm{He}$ diagnosed intussusception and advised immediate removal of the child to St. George's Hospital.

On admission the patient was a bright, healthy-looking child who sat up in bed and did not seem to be much distressed. His pulse was 144 and his temperature was $99 \cdot 6^{\circ} \mathrm{F}$. On examination of the abdomen, movement of the parietes was free; there was little distension and on palpation no rigidity of the abdominal muscles or marked tenderness was noted, but a rounded, sausage-shaped tumour, dull on percussion, was detected extending from the right iliac fossa to the region of the umbilicus and freely moveable. Rectal examination elicited nothing except some mucous discharge. The child vomited some brownish-coloured fluid on two occasions after admission. Mr. Pendlebury was sent for and he decided on immediate operation 26 hours after the onset of acute symptoms. Ether on a cone was the anæsthetic chosen, and the abdomen was opened through a twoinch incision below the umbilicus in the right rectus muscle. The tumour was at once seen and was lifted out of the abdomen ; it was about six inches in length. It showed only a slight degree of congestion and was reduced with little difficulty. After reducing the intussusception which was of the commoner ileo-ciecal variety, there was exhibited about two inches from the cascum a second intussusception of the ileum from one to two inches long; this also was easily reduced. At this spot the infiltration and thickening of the intestinal wall were greatest. The abdomen was closed with fish-gut sutures which were removed 10 days later when the wound was quite healed. The operation lasted 20 minutes. The bowels acted naturally on the third day and abdominally nothing abnormal afterwards occurred.

The patient had been suffering from a slight cough for a few days before admission and, possibly as a result of the ether anrsthesia, be developed a severe attack of bronchitis with a troublesome cough which did not subside for 10 days. The temperature during this time fell gradually from $102^{\circ}$ to normal and thus for some while his condition occasioned considerable anxiety. He was discharged 24 days after the operation and was seen again on Feb. 20th, when the scar seemed to be quite firm.

Remarls by Mr. CADDY. - The case is interesting on account of the very unusual type of intussusception and the slight injury which the peritoneum had received, and the length of time which had elapsed between the onset of symptoms and the operation (26 hours). The absence of collapse or of abdominal pain was marked and one would expect in an intussusception of this nature more acute symptoms.

Remarks by Mr. Pexinentry.-The chief point of interest in this case lies really in the actual anatomy of the intussusception. Clinically it might be described as a "typical case," for it presented all the usual phenomena expected in acute intussusception, from the history of the previons indigestible meal of nuts to the existence of a definite trumour. Perhaps, however, one might mention that the child looked remarkably fit and well considering his condition. This case, I think, comes under the variety denominated iliaco-ileo-colica by Leichtenstern. ${ }^{1}$ I should say that the small intussusception of the ileum occurred first and acting possibly as an irritant tumour caused the further and far more usual ileo-creal form. Certainly, after reduction, which was easily accomplished, the stiffest and most infiltrated and inflamed part of the gut was the few inches occupied by the enteric intussusception. The case admirably illustrates the advantages of early diagnosis and immediate surgical treatment.

\section{MONKWEARMOUTH AND SOUTHWICK HOSPITAL.}

A CASE OF AMPUTATION OF THE RIGHT SHOULDER AND THE RIGHT HIP.

(Under the care of Dr. P. A. Pearcey.)

Simultanious or rapidly consecutive amputations of two limbs are always noteworthy when the limbs are removed at a high level. Most commonly the lower limbs are the seat of double amputation, for it is more likely that both legs will be irreparably damaged than that both arms or one leg and one arm will be thus affected. In the following case 
the arm was amputated at the shoulder-joint and the thigh at the hip-joint, and it is probable that in this respect the case is without parallel. Several cases are on record where portions of three limbs have been amputated ${ }^{2}$ but much less of each limb was removed than in the case recorded below. For gangrene portions of all four limbs have been amputated. ${ }^{2}$ For the notes of the case we are indebted to Mr. Allan Walker, late house surgeon.

A girl, aged 17 years, was admitted to the Monkwearmouth and Southwick Hospital on Nov. 18th, 1901, suffering from the result of an accident caused by her dress having become caught in between two small cog-wheels whilst she was oiling some machinery. On admission she was suffering from great shock but was conscious. Her right arm and right thigh were severely smashed and mutilated and though both brachial and femoral arteries were torn no tourniquet had been applied and there was little or no hæmorrhage-in fact, the limbs were merely hanging by small skin attachments. On seeing the patient, an hour after the accident, as she had been brought over two miles in a cart to the hospital, Dr. Pearcey at once decided to amputate both limbs. Amputation at the shoulder-joint was first performed. Owing to the mutilation some difficulty was experienced in obtaining flaps but a little manipulation overcame this. This having been accomplished Dr. Pearcey proceeded to amputate the right leg at the hip-joint, when the same difficulty of obtaining adequate tlaps was present. Before commencing each amputation Dr. Pearcey ligatured the axillary and femoral arteries respectively. Chloroform was at first administered as an anæsthetic but this was soon changed to ether, only sufficient being given to keep the patient unconscious. Immediately on admission she was given one-thirtieth of a grain of strychnine and half a drachm of ether hypoder. mically. During the operation signs of heart failure commenced and a further hypodermic injection of one-tenth of a grain of strychnine was given. After the amputation at the shoulder was completed these symptoms reappeared and she was infused with three pints of saline solution, one drachm to the pint, at a temperature of $100^{\circ} \mathrm{F}$. This was done whilst the amputation at the hip-joint was proceeding. The operation lasted one and a half hours. The accident had occurred at brickworks and the parts required extensive cleansing. The girl had been swung round and round with the wheel and each time the limbs came in contact with the ground the tissues became embedded with clay and earth, so that it was impossible to obtain clean flaps free from earthy matter. Primary union was consequently not expected ; in fact, the girl's condition appeared perfectly hopeless. Despite this the shoulder did practically heal by first, -ntention. The hip gave more trouble; it suppurated but slowiy healed. The after-treatment was simply that required by such a case - free drainage, stimulants, and gererous diet.

Remarks by Dr. PEARCEY. - The main points of interest in this case are the following: (1) that the girl escaped hæmorrhage; (2) that she survived the operation; and (3) the unique nature of the condition, both arm and leg being amputated at the shoulder- and hip-joints respectively on the same side of the body. I should be glad to know how rnany similar cases have been recorded with the same happy result.

\section{Mttoxital Surcteties.}

\section{PATHOLOGICAL SOCIETY OF LONDON.}

Changes in the Bone Marrow associated nith Suppuration within the Knee-joint. - Neuro-lipomata of the Median Nerve. - " Chyle" Cyst of the Hesentery.-Dermoid Cyst of the Inguinal Canal.-Meningococcus in a Case of Cerebral Tumour.-Tubereulosis in a Python.-Exhibition of Specinens.

A MEETING of this society was held on June 17th, Mr. W. Watson Cherne, C.B., the President, being in the chair.

Dr. A. G. PhenR read a paper on the State of the Bone Marrow of the Femur in a case of Suppuration of the Kneejoint, followed by Profuse Secondary Hæmorrhage. The changes in the medullary tissue were of a double order; there was (1) proliferation of myelocytes and allied cells similar to

1 The Laxcer, April 13th, 1889, p. 730, and Ashurst : Medical and Surgical Reporter, 1888. vol. $\mathrm{i}$ 2 Brit. Med. Jour., 1886, vol. i., p. 81. that which had been recorded in other cases of infective processes and constituting the so-called "myelocytio reaction" to infection; and (2) proliferation of cells of the erythroblastic type, of special interest when viewed in connexion with the severe hæmorrhage that took place some days before death; the characters of the erythroblasts were such as to denote an early stage in their growth. Giant cells were present in considerable number. The proliferation of the cellular constituents of the marrow had advanced to such a degree as to transform its general character; in the place of a tissue consisting almost wholly of fat there was found an opaque, firm, reddish tissue containing an insignificant amount of fat and composed chiefly of the various cells described. Reference was made to recent investigations into the marrow changes attendant on experimentally induced infection with pyogenic organisms and stress was laid on the close similarity between the results of experiment and the marrow lesions which in the present case were found to be clinically associated with suppuration. The importance of such observations, both clinical and experimental, lay in their bearing on the view that the bone-marrow was the source of the polymorphonuclear blood corpuscles, and therefore the chief tissue concerned in the leucocy tosis that accompanied infective diseases. -Dr. H. BATTY SHAW remarked on the absence of karyokinesis in the cells of bone marrow as okserved by Dr. Phear. How was this to be brought into line with the view that bone marrow was the place of origin of the leucocytes?Dr. PHEAR, in reply, said that no blood examination was made because the case did not come under his notice until after death. In regard to the absence of nuclear changes in. the cells other observers had found karyokinetic figures and their absence in this case did not negative the origin of leucocytes from bone marrow.

Mr. H. J. W $\$$ RING narrated a case of Neuro-lipomata of the Median Nerve occurring in a man aged 38 years. The patient, had been quite well until June, 1895, when the right hand and forearm had been crushed by a heavy bar of wood. One year later he suffered pain in the hand and arm which continued until October, 1900, when he was first seen, and resulted in a considerable enlargement of the thumb and forefinger. Amputation was performed in April, 1901, and a diffuse lipomatous growth was found to have formed along the peripheral branches of the median nerve which was also found to be thickened in the forearm. The amputated hand and a skiagram of it were exhibited.-Dr. H. MORLEY FLETCHER suggested the possibility of the case having some relation to von Recklinghausen's disease and asked if there were any tumours along the nerves or pigmentation of the skin in other parts of the body. Was it not a fact that the lipomatous growth had recurred in the limb since the amputation "- Mr. WARING, in reply, said that there were no tumours in any other part of the body.

Dr. JoHY FAWCETT exhibited a "Chyle" Cyst of the Mesentery, which had produced intestinal obstruotion in a child, aged three months, who was admitted into Guy's Hospital on Dec. 13th, 1902, and died the next day. He had been well till Dec. 11th, when diarrhoea and vomiting commenced and continued. At the necropsy an acute intestinal obstruction was found, due to a cyst which had caused a kinking of the small intestine. The cyst was a unilocular cne, of the shape of a pear, and it was distended with a milky fluid. The glands in the mesentery were enlarged. The analysis of the fluid by Mr. J. H. Riffel showed it to be chyle. It contained coagulable proteids and 77 grammes per 100 cubic centimetres of fat. The reaction was alkaline. Sections made from two pieces of the cyst wall showed it to be composed of fibrous and muscular tissue. The characters of this cyst, both as regard its position, contents, and structure, were similar in many ways to those described by Eve, ${ }^{1}$ Moynihan, ${ }^{2}$ and others. The classification previously adopted, based largely upon the contents of these cysts, was not thought satisfactory. The nature of the contents was more or less a matter of chance. The most satisfactory plan would be to classify them all as of embryonic origin (as suggested by $\mathrm{C}$. Dowd in the Annals of Surgery, vol. xxxii., 1900), arising by sequestration from the intestine or its neighbourhood, some from mesoblastic tissue having fibrous or muscular walls or both, others, from hypoblast tissue as well, and therefore showing epithelial structures.

Mr. HERBERT PATERsox showed a Cyst removed from the

1 Transactions of the Royal Medical and Chirurgical Society, vol. $\operatorname{lx} \times \mathbf{x i}$, p. 51 . 